\title{
ADEUS SUDENE, QUE SAUDADE DE CELSO FURTADO!
}

\author{
Prof. Dr. José Borzacchiello da Silva \\ Pós-Graduação em Geografia - Universidade Federal do Ceará \\ Campus do Pici, Bloco 911, CEP 60.455.760, Fortaleza (CE), Brasil
}

Tel: (55 85) 3366.9855 - borza@ufc.br

\begin{abstract}
RESUMO
O artigo foi concebido num contexto político de forte discussão com opiniões controversas sobre a recriação da SUDENE. Parte da constatação da necessidade de se lançar um novo olhar sobre Celso Furtado, este grande nordestino de renome internacional e assim de reacender um espaço necessário ao resgate e compreensão da magnitude da obra e da prática profissional do criador da Sudene. Poucos autores com raríssimas exceções conseguiram dar um enfoque especial à ação da Sudene, posto que o criador e a criatura se confundem. A conjuntura nacional favorece uma releitura do nordeste de Celso Furtado através de novos ângulos, enfocando outra tônica discursiva, centrada no estatuto da permanência de grande parte dos problemas constatados naqueles idos do final dos anos cinqüenta do século passado.
\end{abstract}

Palavras-Chave: desenvolvimento, nordeste, resgate

\begin{abstract}
The article was conceived in a political context of strong debate resulting from controversial opinions concerning the recreation of SUDENE. It starts by pointing out the need to reappraise Celso Furtado, this great nordestino man of international renown and, by so doing, stimulate the emergence of the necessary environment for restoring and understanding the magnitude of the professional work and practice of he who was SUDENE's creator. Very few authors were able to provide a precise view of SUDENE action, since creator and creature confuse themselves. The national conjuncture favors a reevaluation of Celso Furtado's Northeast Region through a new regard, focusing on a new kind of discourse that is based upon the permanence of many problems already detected during the fifties of the 20th century.
\end{abstract}

Key words: development, Northeast Region, restoring

\section{RESUMEN}

El artículo fue elaborado en un contexto político de fuerte discusión con opiniones controversiales sobre la reapertura de SUDENE. Parte de la necesidad de lanzar una nueva mirada a Celso Furtado, este gran nordestino de renombre internacional y así reactivar el espacio necesario para el rescate y comprensión de la magnitud de la obra y práctica profesional de el creador de SUDENE. Pocos autores con raras excepciones consiguen dar un enfoque especial a la acción de SUDENE, puesto que creador y creado se confunden. La coyuntura nacional favorece una relectura del nordeste de Celso Furtado a través de nuevos ángulos, enfocando otra tónica discursiva, centrada en el estatuto de la permanencia de gran parte de los problemas detectados al final de los años cincuenta del siglo pasado.

Palabras-clave: desarrollo, Nordeste, reanalisies

\section{INTRODUÇÃO}

O governo Lula prometeu a recriação da Sudene, extinta na gestão de FHC. Grupos de trabalho foram instituídos com a missão de reinstalar o órgão. Malgrado o esforço da equipe técnica, o governo se aproxima de seu último ano e a Sudene permanece no papel. A CCJ - Comissão de Constituição, Justiça e Cidadania aprovou no dia 07 de dezembro de 2005, o substitutivo do senador Tasso Jereissati, ao Projeto de Lei da Câmara - Complementar 59/04, que recria aquele órgão. Como explicar esta morosidade? A meu ver, por mais urgente e necessário, não há mais lugar para um órgão voltado ao desenvolvimento regional, nos moldes da antiga Sudene. Seu suntuoso edifício no Recife, muito bem localizado, como não poderia deixar de ser, em frente à Universidade Federal de Pernambuco, instituição que forneceu quadros de primeira linha aquele órgão desde sua criação em dezembro de 1959. A meu ver, por mais que urgente e necessário, não há mais lugar para um órgão voltado ao desenvolvimento regional. Ele surgiu em outro contexto, quando a integração nacional era preocupação política de estado a partir da constatação da "região" como espaço delimitado, desintegrado do contexto nacional exigindo uma ação oficial mais enérgica. Região era o conceito 
chave e a integração do espaço uma meta. Hoje o conceito dominante é o de território, que por sua natureza, lida com frações, com fragmentos. Há cinqüenta anos atrás, o ator principal era o Estado e as ações eram governamentais. Hoje a gestão é "compartilhada" com realce para as empresas que assumem destacado papel na identificação de problemas e possíveis intervenções. O país mudou muito. A correlação de forças é outra. A Sudene hoje ficaria certamente, deslocada. Por isso cada vez mais, cabe destacar a importância que ela assumiu na gestão regional. É bem verdade que a região se fragmentou. As relações mar e sertão foram fortemente abaladas. Sertão passou a ser semi-árido e o litoral se desprendeu da superfície sertaneja, adquirindo uma certa autonomia. Do quadro original, algumas permanências - enorme hiato social que separa o Brasil e a miséria ronda as metrópoles nordestinas com infindáveis cordões de habitação precária marcados pela carência absoluta. Celso Furtado não poderia imaginar a situação belicosa que se instaurou no nordeste a partir dos anos 90. Tudo por uma indústria. Estados e municípios dilapidaram parte de seus recursos face uma perversa 'guerra fiscal'. As exigências impostas pelas empresas em busca de incentivos é a mostra da ausência de um órgão catalisador das ações de desenvolvimento. O que diria o fundador da Sudene ao ver esse quadro? O Brasil deve uma leitura mais acurada sobre a importância de Celso Furtado no Brasil e especialmente, no nordeste. Imaginemos o que diria hoje nosso mais renomado economista e pensador do desenvolvimento, se visse a permanência da maioria dos problemas por ele identificados. Como reagiria diante de discursos e falas que se repetem? E o sertão, de que forma reagiu às ações da Sudene, que construiu um retrato de corpo inteiro do nordeste, profundo o suficiente e capaz de mostrar os problemas e as possibilidades da "região". O GTDN - Grupo de Trabalho para o Desenvolvimento do Nordeste assim o fez ao elaborar o documento "Uma Política de Desenvolvimento Econômico para o Nordeste". O GTDN foi constituído no ano de 1956 pelo presidente Juscelino Kubitschek, ficando Celso Furtado responsável pela sua coordenação. Um texto profundo e necessário até hoje, obrigatório de ser lido pelos gestores para que se constate as permanências de problemas que afetam de cheio a qualidade de vida dos nordestinos.

Concentrando uma das maiores densidades de miseráveis em região semi-árida, correspondente à superfície sertaneja, o nordeste exigia levantamentos, dados e informações estatísticas capazes de fundamentar projetos e atrair investidores. Urgia provar que o nordeste era um bom negócio, sem contudo inseri-lo numa perspectiva mercadológica dominada por perversas relações de produção. Os argumentos traziam no seu bojo o discurso das oportunidades geradas pelo desenvolvimento. A crença, como era consensual, recaia na industrialização como única possibilidade de romper com o acirrado desequilíbrio regional. A questão ecológica e os problemas ambientais não estavam postos naquela época.

Estatísticas finas foram aplicadas, mapas detalhados foram elaborados expondo os problemas que logo identificados foram transformados em temas explicativos da natureza nordestina e do cotidiano de seu povo. O Brasil e o nordeste mudaram muito. O problema é que a região continua como centro da mais miserável e a mais problemática do país. Até que ponto uma nova Sudene teria condição de reverter esse quadro?

As exigências impostas pelas empresas em busca de incentivos evidencia ausência de um órgão catalisador das ações de desenvolvimento como aquele exercido pela Sudene. Hoje cabe uma leitura crítica sob vários enfoques reunindo profissionais, políticos, técnicos e professores universitários em torno da grande empreitada encetada por Celso Furtado. Uma (re)visitação em sua obra despertará, certamente, grande interesse dos governantes, intelectuais e do grande público.

\section{CELSO FURTADO}

Partimos do pressuposto da necessidade de se lançar um novo olhar sobre este grande nordestino de renome internacional capaz de preencher um espaço necessário ao resgate e compreensão da magnitude da obra e da prática profissional do criador da Sudene. 
Poucos autores com raríssimas exceções conseguiram dar um enfoque especial à ação da Sudene, posto que o criador e a criação de confundem. A conjuntura nacional favorece uma releitura do nordeste de Celso Furtado através de novos ângulos, enfocando outra tônica discursiva, centrada no estatuto da permanência de grande parte dos problemas constados naqueles idos do final dos anos cinqüenta do século passado. Um novo olhar permite descortinar novas possibilidades de percorrer o velho nordeste profundo, de suas bordas aos seus recantos mais recônditos, de se antever no arcaísmo de certas estruturas, o novo engendrado em novas relações de produção, nos embates e no desenho de novas formas organizativas. Esse enfoque é necessário e quando realizado, preencherá um espaço necessário ao resgate e compreensão da magnitude da obra e da prática profissional de Celso Furtado.

Seu grande mérito foi organizar em torno de um órgão voltado ao desenvolvimento regional, uma equipe composta por profissionais atuantes e preocupados em construir um outro nordeste. Para isso era necessário construir um retrato de corpo inteiro, profundo o suficiente e capaz de mostrar os problemas e as possibilidades da "região". O GTDN - Grupo de Trabalho para o Desenvolvimento do Nordeste assim o fez ao elaborar o documento "Uma Política de Desenvolvimento Econômico para o Nordeste". O texto, pela sua qualidade, e malgrado seus quase cinqüenta anos, com alguns ajustes, certamente subsidiará questões prementes que ainda afligem a sociedade nordestina, presentes em vários aspectos da vida de seu povo. Celso Furtado inaugurou com uma equipe séria e competente uma forma ética de fazer ciência engajada, alimentada na crença de que é possível a partir da ciência, ampliar o conhecimento de nossa realidade e subsidiar políticas sociais mais conseqüentes.

Celso era um conhecedor profundo dos problemas da região. Cercou-se de pessoal de excepcional potencial crítico, o que adicionou acuidade e vontade de mudar. Um saber fazer que fazia com que esses pesquisadores fossem além de seu refinado balizamento teórico e capacidade de elaborar relatórios analíticos de reconhecida consistência. Era a práxis que se realizava naquele final dos anos cinqüenta e início dos sessenta. Celso tinha exacerbada consciência crítica, pouco discursada em seus pronunciamentos, muito evidenciada, entretanto, em sua prática. Parecia exigir por dever de ofício, dedicação exclusiva em sua coordenação à frente da Sudene. A saga desse profissional resultou em viagens, expedições, excursões e outros deslocamentos necessários, muitos emergenciais, pelo território nordestino. Conhecimento calcado na realidade e teoria adquirida em anos de lides administrativas e acadêmicas. Sua equipe era constituída por profissionais com sofisticada especialização em suas áreas científicas, que tinham no nordeste, o campo primordial de suas pesquisas.

A Sudene resultou desse amálgama entre fazer a gestão do território utilizando corretamente o método científico e a realidade empírica, seqüenciando suas ações e procedimentos de forma lógica coerente.

O nordeste foi contemplado com uma nova interpretação cuja qualidade foi validada pela crítica internacional. A Sudene tornou-se referência logo após sua criação. Atraiu os olhares do mundo. Fundada em acurada leitura da realidade, há muito exigida pelo nordeste brasileiro que aguardava uma ação oficial mais incisiva.

Fundados no pressuposto da capacidade da indústria gerar novos postos de trabalho, foram criados pólos e distritos industriais. Os projetos foram conduzidos com acuidade, calcados em princípios isonômicos, tentando atender as demandas de todos os estados conforme sua formação econômica.

A natureza com todo o seu potencial foi estudada e cartografada. As relações, entrecruzamentos foram discutidos. A sociedade foi levada em conta. Explorando um roteiro de múltiplas abordagens, criadas e recriadas e, melhor ainda, reunidas num discurso competente e de qualidade, a metodologia permitiu um olhar especializado - o olhar sagaz, capaz de aproximar o nordeste no que ele tem de real e de concreto na objetividade de sua forma, seus problemas estruturais e muito mais, na subjetividade das relações onde as vicissitudes do cotidiano do mundo estão presentes nas ter- 
ritorialidades transitórias produzidas e as cristalizações espaciais decorrentes das ações e emoções dos diferentes atores sociais - os nordestinos - na busca incessante de transformar a realidade a partir de suas vivências e experiências.

A profundidade das pesquisas permitiram uma revelação, um desocultamento da real situação do nordeste. A região tão bem descrita nos romances com ambiência na Zona da Mata ou no Sertão mostrou seu rosto concreto e assustou. O desnudamento da realidade nordestina, incomodou muitos políticos que faziam da miséria, excelente mercadoria eleitoral. Os estudos e projetos trouxeram à tona, cenas de um cotidiano novo para o chamado "Sul maravilha" e antigo para milhões de nordestinos em suas grotas no sertão profundo. Espaços rurais diferenciados no sertão, no agreste, no litoral foram revelados. Os núcleos urbanos nordestinos mudavam sua fisionomia à medida que novos espaços eram incorporados às relações de produção impostas pelo sudeste do país. A espessura das trajetórias de vida dos trabalhadores rurais em busca pela terra para plantar continha uma longa temporalidade. A Sudene de seus primórdios renovou o compromisso de perspicaz observadora de um acelerado processo de mudanças que a região conhecia.

A Sudene surgiu da perseverança de seu proponente em reunir sob a coordenação daquele órgão um conjunto de propostas capazes de buscar solidez e profundidade nas ações implementadas. O saber popular era reconhecido e, por sua vez, agregava a competência e o vigor científico dos técnicos envolvidos na ação. A Sudene enfoca o nordeste sob um novo olhar, colocando à disposição dos brasileiros, projetos voltados ao desenvolvimento, concebidos sob forte teor analítico e no reconhecimento e interpretação da região sujeito da intervenção. Durante sua curta existência autônoma, conforme os ditames de Celso Furtado, os profissionais vinculados ao universo Sudene elaboraram pesquisas que são referência até nossos dias. Elas comprovam um conhecimento profundo da situação do nordeste, agora expandido, compreendendo o Polígono das Secas, ultrapassando os limites estadualizados formadores do chamado nordeste tradicional. As pesquisas contém e expressam um discurso competente, quanto à localização, ocorrência e extensão de problemas enfocados, sugerindo de imediato as ações capazes senão de extinguí-los, pelo menos de atenuálos. Celso Furtado conhece a fundo o fulcro dos problemas do nordeste. Sua capacidade crítica identifica as possibilidades e os limites em sua saga desenvolvimentista. Respondendo a Manuel Correia de Andrade que lhe perguntou "Eu tenho a impressão, pelo que vi ali, que você considera necessária uma reforma agrária na região do semi-árido, e que sem essa reforma agrária não pode haver mudança de desenvolvimento da região, assim respondeu Celso Furtado - "A lei de irrigação que eu tentei fazer quando estava na Sudene era uma pequena reforma agrária. A idéia era investir dinheiro público no setor rural, em grande escala. Isso só seria possível modificando a estrutura agrária. Mas fui derrotado. Minha opinião sobre isso é clara e definitiva. Da mesma maneira, me recordo da subutilização de terra na Zona da Mata, e do desinteresse do pessoal dali pela produção de alimentos. Consegui desapropriar o Engenho de Tiriri para fazer divisão de terra e produção de alimentos. O que pudemos fazer, fizemos, mas foi muito pouco". ${ }^{1}$

\section{NORDESTE: PERMANÊNCIAS E MUTAÇÕES}

O nordeste permanece como 'a região' no país. Apresentando os maiores índices indicadores do atraso, traduz o Brasil sub-desenvolvido em contraste com as demais regiões brasileiras. As regiões no país nada mais são que resultado de um recorte espacial determinado pelo IBGE, a ser seguido pela administração dos serviços públicos. Neste sentido, "a região é, portanto, concreta, observável e delimitável"(CASTRO-1992). Entretanto, esse recorte está longe de transformar os estados integrantes das regiões em recortes identitários, como acontece no nordeste. No Brasil não há o hábito de se classificar as pessoas como "sudestinas", "sulistas" ou "centro-oestinas". No máximo aplica-se a denominação "sulista" para aqueles que não são nordestinos, de sorte que apenas o nordeste tem a função de distinguir os nascidos em seu recorte como portadores de índices de 
desenvolvimento inferiores aos alcançados pelo restante do país. A questão do atraso nordestino é antiga no país. Discutindo o regionalismo nordestino, assim se refere Castro, "Nossa questão central está referenciada à elite nordestina que imprime caráter conservador à organização sócioeconômica regional". As teses do desequilíbrio regional só foram formuladas a partir dos anos sessenta. Entretanto, a leitura da realidade que associava atraso à ocorrência de secas datam do tempo do império. Contraditoriamente, o nordeste apresenta elevados índices de crescimento em várias atividades, especialmente, no setor do turismo, com investimentos de grande monta no litoral.

Com o turismo o nordeste ganha um grande porte que permite ser (re)visitado sob o prisma das políticas públicas, agora voltadas para explorar mais aquele aspecto que era sua negação - o sol, o calor, a praia. Portador de raras belezas em seu contorno, o litoral nordestino atraiu novos olhares e despertou interesse do capital internacional especializado no turismo. No setor industrial as intervenções oficiais voltaram-se para a lavoura irrigada estimulada pelos agro-negócios, uma mescla do conhecimento teórico adquirido na fase da Sudene e a constatação empírica das possibilidades da prática de atividades que criassem condições de trabalho no campo. Entretanto, essa atividade ficou restrita às áreas favorecidas pela captação de água pelas grandes barragens, formando verdadeiras ilhas e corredores ao longo do São Francisco na Bahia e Pernambuco e manchas verdes noutros estados nordestinos. Bahia, Haesbaert(1996) Santos Filho(1989), Maranhão e Piauí, integraram-se ao território da soja organizado a partir do centro-oeste do país.

É necessário buscar compreender as relações que se estabelecem hoje com a interiorização da indústria e os antigos percursos realizados que garantiram as bases do povoamento e o crescimento das cidades, a formação de um sistema de redes de integração do território com suas temporalidades diferenciadas. O nordeste era o dentro, o Brasil recôndito e o Brasil de fora exposto em sua imensa litoralidade nas transações comerciais realizadas em seus portos. A região expandida pelos caminhos da pecuária se integra à modernidade através das estradas virtuais. As cidades, especialmente as de porte médio devem ser discutidas na perspectiva sob o aspecto de sua expansão urbana e organização do espaço. São hoje lugares difusores de inovações e de comando com forte papel na triagem dos fluxos migratórios para as capitais e espaços metropolitanos. O nordeste real deve ser buscado insistentemente, sem no entanto, perder de vista excelentes imagens e descrições regionais contidas nos romances de José Lins do Rego, Graciliano Ramos, Raquel de Queiroz, Jorge Amado e muitos outros.

A natureza nordestina continua despertando interesse, entretanto, enquanto eco-sistema e biomassa está longe de merecer uma atenção correspondente à sua importância. Apesar dos problemas provocados pela desigual distribuição de chuvas trata-se de área de alta densidade, ocupada por expressivo percentual da população mais pobre do país. No semi-árido localizam-se os bolsões de população com os mais baixos índices de escolaridade e de renda. O estudos atuais voltados à interpretação e análise das condições naturais, compreendendo a compartimentação geoambiental, as unidades morfoestruturais, características climáticas, recursos hídricos e a vegetação ligam-se mais aos interesses dos agro-negócios. Têm sido aprofundados os estudos que identificam os problemas ambientais, tendo em vista a criação de unidades de conservação. Para o turismo importa identificar os diferentes tipos de litoral, tendo em vista a instalação de grandes resorts.

$\mathrm{Na}$ tentativa de ultrapassar os limites impostos pela natureza e munidos de antigas aspirações que datam do século XIX, o governo Lula elegeu a captura e transporte de águas do Rio São Francisco como meta de seu governo. O discurso oficial recorre ao velho jargão de "matar a sede" de milhões de nordestinos que vivem à margem das conquistas sociais alcançadas pelo país. Os estudos realizados pelo governo têm sido objeto de severas críticas, provocando cismas entre defensores e opositores. Mais importante que a discussão acirrada que se trava entre os especialistas é a nítida cisão que se vê entre os estados nordestinos. Quando da Sudene, reuniam-se os governadores no Conselho Diretor para discutir o acesso aos recursos e as políticas prioritárias. Agora Bahia, Sergipe e Alagoas colocam-se contrários a qualquer desvio de águas do São Francisco. Ceará, Paraíba 
e Pernambuco são os maiores defensores. As análises que norteiam o projeto fundem natureza e sociedade no nordeste. A persistência do discurso do desenvolvimento regional aparece novamente nos anos 90, quando da elaboração do Áridas, projeto que desenha novas alternativas, assumindo uma postura minguada do que foi o GTDN. Concebido num quadro diferenciado que retorna ao "Polígono das Secas", identifica no quadro natural e, no princípio do "desenvolvimento sustentável”, uma possibilidade de saída para a região.

Na Introdução do Projeto Áridas, Beni Veras, ex- Ministro-Chefe da Secretaria de Planejamento, assim se referiu "Depois de quatro décadas de políticas orientadas de desenvolvimento regional, a partir da criação do BNB e da Sudene nos anos 50, as desigualdades regionais continuam graves no país (...) Ao tempo em que se constata a persistência das desigualdades regionais e sociais, verificase também o desgaste do modelo de planejamento e de políticas de desenvolvimento regional". ${ }^{2}$

Vem à tona novamente as discussões em torno da contradição que une e separa litoral e sertão. Litoral sem chuva é promessa de excelentes negócios para o turismo. Sertão sem chuva é excepcional para as lavouras irrigadas. Para os sertanejos, a grande maioria, a estiagem ainda é o maior entrave à sua permanência. Temas inovadores tem sido pautados nas discussões. O nível de profundidade tem íntima relação com a formação recente de quadros com a afirmação da política acadêmica envolvendo, inclusive, a pós-graduação.

\section{NORDESTE: O MITO DO DESENVOLVIMENTO}

A busca do desenvolvimento tem marcado a saga nordestina. Há uma forte associação entre os conceitos de região e desenvolvimento. A propósito, escreveu Rist (1996) “ Pode, com efeito se espantar pelo fato que cinqüenta anos depois de se estender oficialmente nos países do Sul e colocado como ordem do dia da comunidade internacional, o 'desenvolvimento'ainda não se realizou"' . Entre nós, a esperança do desenvolvimento é uma permanência, especialmente na região percebida como um recorte como é o caso do nordeste. A idéia de desenvolvimento mobilizou grande parte da intelectualidade brasileira em busca de novas propostas para o nordeste. Concepções e percursos diferentes norteiam a prática da região, ora esgarçada, ora restrita, conforme o enfoque realizado ou o conceito aplicado para sua leitura. Concretamente, malgrado o discurso ambiental e as conquistas sindicais, no nordeste contemporâneo, persiste a competição para atrair indústrias, o turismo e todas as atividades que envolvem esse setor, tendo em vista renovar as tradicionais técnicas remanescentes no mundo rural. Ao lado dos programas oficiais que privilegiam a reestruturação produtiva da agricultura e a melhoria do plantel da pecuária, os movimentos dos sem terra - MST se mobiliza instalando assentamentos em vários municípios. Terra, água, seca e acesso aos bens necessários à reprodução da vida são as maiores reivindicações dos nordestinos ainda não atingidos pela tão esperada onda desenvolvimentista.

Assim passaram os anos, quase cinqüenta, e o nordeste é ainda a expressão da região em nosso país. A região que deixou de ser discutida com a profundidade como o fez Celso Furtado e sua equipe e que ficou, contraditoriamente, esquecida. De região problema o nordeste foi assumindo múltiplas identidades, novas feições. A discussão sobre a permanência da região, enquanto lugar do atraso saiu do receituário político. Só vinha à tona nos comentários econômicos dos noticiários. Fica difícil insistir no discurso da miséria e do infortúnio do nordeste, quando a região é campeã na atração de divisas com o turismo, cultivo de frutas e flores tropicais e outros produtos disponibilizados em diversos mercados. Resultado de uma prática implantada por novas lideranças políticas estaduais, tem-se um quadro que coloca o nordeste em evidência face à guerra fiscal que se estabeleceu no país nos últimos anos. O nordeste fica em situação de vantagem no conjunto nacional, especialmente Bahia, Ceará e Pernambuco que conheceram a instalação de novas indústrias até então localizadas no sul e sudeste do país. No interior do nordeste por sua vez, algumas áreas têm alcançado altos índices de lucratividade, especialmente, as de Mossoró e o Baixo Vale do Açu, 
no Rio Grande do Norte, o Baixo Jaguaribe, no Ceará e a área de lavoura irrigada do São Francisco em Petrolina, além da incorporação do oeste baiano com as lavouras de soja, trazidas pelos gaúchos que ali se radicaram. ${ }^{4}$

A dinâmica interna regional relegava o recorte clássico denominado nordeste a um segundo plano. Demarcado com nitidez no território, o velho nordeste, agora fragmentado segue outra direção. Velhas questões vinculando seca, flagelo, fome, violência, saque, ultrapassam os limites prévios da região, tornando-se questão nacional. O nordeste enquanto recorte, quando identificado como região, desencadeou um conjunto de políticas que objetivava, antes de mais nada, superar o atraso que fora verificado naquela porção do território brasileiro. Desenvolveu "uma forma típica da 'rationale' do capitalismo monopolista, e ao mesmo tempo do Estado ante nação, que tenta reconstruir pelo planejamento a comunidade ilusória', pela qual diz representar a Nação”.(OLIVEIRA, 1977).

\section{CONSIDERAÇÕES FINAIS}

Celso Furtado acompanhou no exílio, a captura da Sudene pelas oligarquias, enunciada em contundente crítica elaborada por Oliveira(1977) . A identificação anterior de vários nordestes, Freyre (1958), Menezes (1937) alentava nele, o desejo de superação desses fragmentos, em busca de um nordeste capaz de ocupar lugar de destaque no cenário nacional.

Que saudades daquele tempo, quando ser profissional da Sudene era expressão de experiência, de compromisso! Celso Furtado deixou saudades. Seus estudos privilegiaram a abordagem das questões mais prementes do nordeste com elevado teor analítico respaldado na realidade e embasado em fundamentos teóricos de vanguarda. Celso Furtado emprestou prestígio ao planejamento regional concebendo a intervenção numa perspectiva integral marcada pela coerência e segurança teórico-metodológica. A experiência Sudene, a obra de Celso Furtado, sua vida tornaram-se tema obrigatório nas lides governamentais e acadêmicas de todo mundo.

\section{NOTAS}

(1) Seca e Poder: entrevista com Celso Furtado, São Paulo, Fundação Perseu Abramo, 1998 (entrevistadores: Maria da Conceição Tavares, Manuel Correia de Andrade, Raimundo Pereira) pp 46/47

(2) NORDESTE - Uma Estratégia de Desenvolvimento Sustentável - Projeto Áridas, Brasília, MPO, 1995

(3) RIST, Gilbert, Le Développement: Histoire d'une croyance occidentale, Paris, Presses de la Fondation Nationale des Sciences Politiques, 1996

(4) VER: CASTRO, Iná Elias de, Secas versus seca. Novos interesses, novos territórios, novos discursos no Nordeste, In:CASTRO, Iná Elias et alii, BRASIL, Questões Atuais da Reorganização do Território, Rio de Janeiro, Bertrand Brasil, 1996. HAESBAERT, Rogério, "Gaúchos" e baianos no "novo"Nordeste: entre a globalização econômica e a reinvenção das identidades territoriais. In: , BRASIL, Questões Atuais da Reorganização do Território, Rio de Janeiro, Bertrand Brasil, 1996; CAVALCANTE, Enoque Gomes, Geo-Economia do Semi-Árido Irrigado, Recife, Editora Universitária/UFPE, 1997.

\section{REFERÊNCIA BIBLIOGRÁFICA}

TAVARES, M. C.; ANDRADE, M. C.; PEREIRA, R. (entrevistadores) Seca e Poder: entrevista com Celso Furtado. São Paulo: Fundação Perseu Abramo, 1998. pp 46/47

CASTRO, Iná Elias de. O Mito da Necessidade: Discurso e Prática do Regionalismo Nordestino. Rio de Janeiro: Editora Bertrand Brasil S. A, 1992 - pp.33

CAVALCANTE, Enoque Gomes. Geo-Economia do Semi-Árido Irrigado. Recife: Editora Universitária/ UFPE, 1997.

HAESBAERT, Rogério, , "Gaúchos" e baianos no "novo" Nordeste: entre a globalização econômica e a reinvenção das identidades territoriais. In: , BRASIL, Questões Atuais da Reorganização do Território. Rio de Janeiro: Bertrand Brasil, 1996. 
SANTOS Filho, Milton. O processo de urbanização do oeste baiano. Recife: SUDENE, 1989.

NORDESTE - Uma Estratégia de Desenvolvimento Sustentável - Projeto Áridas. Brasília: MPO, 1995.

RIST, Gilbert. Le Développement: Histoire d'une croyance occidentale. Paris: Presses de la Fondation Nationale des Sciences Politiques, 1996.

OLIVEIRA, Francisco. Elegia para uma re(li)gião. Rio de Janeiro, 2a. ed. Paz e Terra, 1977.

FREYRE, Gilberto. Casa Grande \& Senzala: Formação da família brasileira sob o regime patriarcal. 9a. ed. Rio de Janeiro: Ed. José Olympio, 1958.

MENEZES, Djacir. O Outro Nordeste. Rio de Janeiro: Livraria José Olympio Editora, 1937.

Trabalho enviado em setembro de 2009

Trabalho aceito em dezembro de 2009 